\title{
The hidden dangers of a cancer diagnosis
}

\author{
()) (1) $\Theta$ OPEN ACCESS
}

Patients have a heightened risk of injury in the weeks before and after a diagnosis

\author{
Holly G Prigerson professor of medicine ${ }^{1}$, Susan C Vaughan assistant professor of clinical \\ psychiatry $^{2}$, Wendy G Lichtenthal assisting attending psychologist ${ }^{3}$
}

${ }^{1}$ Center for Research on End-of-Life Care, Department of Medicine, Weill Cornell Medicine, New York, NY 10065, USA; ${ }^{2}$ Department of Psychiatry, Columbia College of Physicians and Surgeons, New York, NY 10032, USA; ${ }^{3}$ Department of Psychiatry and Behavioral Sciences, Memorial Sloan Kettering Cancer Center, New York, NY 10065, USA

No one can deny that medical advances have prolonged life and improved the human condition. Yet it is equally true that outcomes of medical encounters are neither universally beneficial nor benign. As long ago as $19 \mathrm{BC}$, Virgil wrote that it is often the case that "the disease worsens with the treatment." In the linked paper, Shen and colleagues (doi:10.1136/bmj. i4218) ${ }^{2}$ extend this assertion to "the disease worsens with the diagnosis." They sought to determine how a diagnosis of cancer, apart from the disease and its treatment, heightens the risk of injury before and after the diagnostic period. They hypothesized that injury secondary to a diagnosis results from both medical complications and psychosocial stress.

Shen and colleagues analysed hospital discharge diagnoses related to injury in over 720000 patients with cancer in Sweden and compared a diagnostic period (the 16 weeks before and after a diagnosis) with a control period the year before diagnosis. ${ }^{2}$ Consistent with previous research, they found that injuries among patients with cancer were common ${ }^{34}$ as well as potentially life threatening. ${ }^{45}$ The study found that in over 720 000 patients there were 15000 injuries severe enough to result in admission to hospital during their diagnostic period.Given that they examined only those injuries that resulted in admission, the estimates of injury related to cancer diagnosis were conservative. Because data were derived from Sweden's nationwide patient registry, the sampling was admirably large, remarkably representative, and minimally biased.

To characterize the types of injuries associated with a cancer diagnosis, Shen and colleagues sorted injuries into those that were "iatrogenic" and those that were not. ${ }^{2}$ Interestingly, Bleuler, a psychiatrist, invented the term "iatrogenic illness" to describe a patient's psychological distress caused by a physician's communication of a poor prognosis. ${ }^{6}$ Here, the term is used to refer to medically, not psychologically, induced injuries. To probe into the psychological distress caused by a physician's communication of a diagnosis of cancer is beyond the scope and capacity of registry data. Such an investigation would require detailed questioning of patients and physicians about thoughts and feelings aroused by the diagnosis. Nevertheless, the study shows interesting patterns suggesting that clinicians and researchers should pay more attention to the negative influence of a diagnosis of cancer on the health and wellbeing of patients.

Shen and colleagues found that people with a diagnosis of cancer experienced significantly more iatrogenic injuries in the weeks before and after their diagnosis compared with the year before. ${ }^{2}$ That the process of diagnosis of cancer can result in injuries such as bleeding and infections is worth noting, even though it's unsurprising. The knowledge that younger, better educated patients, those with a history of psychiatric illness, and those with certain cancers (such as central nervous system and colorectal cancers) are at an increased risk of injury can help to inform how the diagnostic period is managed in these more vulnerable groups. The variability in injuries by type of cancer suggests that iatrogenic harm resulting from diagnoses other than cancer might also show dramatic differences in injury by disease.

Of potentially greater interest, this study showed that the risk of "unintentional" "non-iatrogenic" injuries such as "accidents" peaked four weeks before the diagnosis. So clinicians should warn patients who are worried about the possibility of cancer that poor concentration and preoccupation puts them at heightened risk of potentially serious mishaps making them "accident prone." Prevention efforts might include the recommendation that patients awaiting diagnostic results slow down and be deliberate and mindful of their surroundings. Arming patients with a toolkit of coping strategies to help them manage preoccupying levels of anxiety might also be helpful. By contrast, the incidence of intentional injuries increased markedly immediately after the cancer diagnosis. This finding suggests that oncologists should pay close attention to how a diagnosis affects a patient's mental health. They could join 
forces with mental health providers and nurses to screen and, when indicated, intervene with patients who are experiencing severe distress and psychological symptoms, as this heightens their risk of suicidal thoughts or actions. ${ }^{7}$ Patients with cancer who lack social support and a sense of self efficacy (that is, belief in one's ability to succeed in specific situations or accomplish a task) might feel isolated, helpless, and desperate. Some might consider suicide preferable to death from cancer. Psychosocial interventions to help patients cope with their fears and regain a sense of control should be offered. ${ }^{89}$ Patients cannot undo their diagnosis, but effective and empowering interventions could limit the extent to which they become undone by it.

Competing interests: We have read and understood the BMJ Group policy on declaration of interests and declare the following interests: none.

Provenance and peer review: Commissioned; not peer reviewed.

Virgil , Fagles R, Knox B. The Aeneid. Penguin Books, 2008.

2 Shen Q, Lu D, Schelin M, et al. Injuries before and after diagnosis of cancer: nationwide register based study. BMJ 2016;354:14208.
3 Weingart SN, Wilson RM, Gibberd RW, Harrison B. Epidemiology of medical error. BMJ 2000;320:774-7. doi:10.1136/bmj.320.7237.774 pmid:10720365.

4 Camidge DR, Stockton DL, Frame S, Wood R, Bain M, Bateman DN. Hospital admissions and deaths relating to deliberate self-harm and accidents within 5 years of a cancer diagnosis: a national study in Scotland, UK. Br J Cancer 2007;96:752-7. doi:10.1038/sj. bjc.6603617 pmid:17299389.

5 Baade PD, Fritschi L, Eakin EG. Non-cancer mortality among people diagnosed with cancer (Australia). Cancer Causes Control 2006:17:287-97 doi:10.1007/s10552-0050530-0 pmid:16489536.

6 Bleuler E. Textbook of psychiatry. Macmillan, 1924

7 Spencer RJ, Ray A, Pirl WF, Prigerson HG. Clinical correlates of suicidal thoughts in patients with advanced cancer. Am J Geriatr Psychiatry 2012;20:327-36. doi:10.1097/ JGP.0b013e318233171a pmid:21989317.

8 Linden W, Girgis A. Psychological treatment outcomes for cancer patients: what do meta-analyses tell us about distress reduction? Psychooncology 2012;21:343-50. doi:10. 1002/pon.2035 pmid:21882287

9 Faller H, Schuler M, Richard M, Heckl U, Weis J, Küffner R. Effects of psycho-oncologic interventions on emotional distress and quality of life in adult patients with cancer: systematic review and meta-analysis. J Clin Oncol 2013;31:782-93. doi:10.1200/JCO. 2011.40.8922 pmid:23319686

Published by the BMJ Publishing Group Limited. For permission to use (where not already granted under a licence) please go to http://group.bmj.com/group/rights-licensing/ permissions

This is an Open Access article distributed in accordance with the Creative Commons Attribution Non Commercial (CC BY-NC 3.0) license, which permits others to distribute, remix, adapt, build upon this work non-commercially, and license their derivative works on different terms, provided the original work is properly cited and the use is non-commercial. See: http://creativecommons.org/licenses/by-nc/3.0/. 